Autorschaft als historische Konstruktion 


\section{Autorschaft als historische \\ Konstruktion}

Arnold Schönberg -

Vorgänger, Zeitgenossen, Nachfolger und Interpreten

Hrsg. im Auftrag des

Staatlichen Instituts für Musikforschung

Preußischer Kulturbesitz von

Andreas Meyer und Ullrich Scheideler

Verlag J. B. Metzler

Stuttgart - Weimar 
Die Deutsche Bibliothek - CIP-Einheitsaufnahme

Autorschaft als historische Konstruktion : Arnold Schönberg : Vorgänger, Zeitgenossen, Nachfolger und Interpreten / hrsg. von Andreas Meyer im Auftr. des Staatlichen Instituts für Musikforschung Preußischer Kulturbesitz.

- Stuttgart ; Weimar : Metzler, 2001

ISBN 978-3-476-01839-7

ISBN 978-3-476-01839-7

ISBN 978-3-476-02771-9 (eBook)

DOI 10.1007/978-3-476-02771-9

Dieses Werk einschließlich aller seiner Teile ist urheberrechtlich geschützt. Jede Verwertung außerhalb der engen Grenzen des Urheberrechtsgesetzes ist ohne Zustimmung des Verlages unzulässig und strafbar. Das gilt insbesondere für Vervielfältigungen, Übersetzungen, Mikroverfilmungen und die Einspeicherung und Verarbeitung in elektronischen Systemen.

(C) 2001 Springer-Verlag GmbH Deutschland Ursprünglich erschienen bei J. B. Metzlersche Verlagsbuchhandlung und Carl Ernst Poeschel Verlag GmbH in Stuttgart 2001 www.metzlerverlag.de inf@metzlerverlag 


\section{Inhalt}

ANDREAS MEYER/ULLRICH SCHEIDELER

Einleitung

HANS-JOACHIM HINRICHSEN

Schönberg, Bach und der Kontrapunkt

Zur Konstruktion einer Legitimationsfigur

MATTHIAS SCHMIDT

Klassiker? Mozart-Beethoven-Schönberg

CHRISTIAN MARTIN SCHMIDT

Schönberg und Brahms

\section{MATTHIAS SCHÄFERS}

"... daß dasjenige, das den Anstoß zur Entwicklung gegeben hat, auch das erste ist, das uns wieder abstößt ..." Arnold Schönberg und Richard Strauss

ULLRICH SCHEIDELER

Einfall - Material - Geschichte

Zur Bedeutung dieser Kategorien im Musikdenken

Pfitzners und Schönbergs um 1910

FELIX WÖRNER

"Nachahmung" und "Überbietung" durch Webern

Aspekte einer komplexen Interaktion

ANSELM GERHARD

Farben und Formen in einem "Totentanz der Prinzipien" Arnold Schönbergs Pierrot lunaire und das "Zerfließen" der Tradition 
JOSEPH H. AUNER

Schönberg und sein Publikum im Jahr 1930:

Die Sechs Stücke für Männerchor a cappella op. 35

GIANMARIO BORIO

Zwölftontechnik und Formenlehre

$\mathrm{Zu}$ den Abhandlungen von René Leibowitz und Josef Rufer

INGE KOVÁCS

Warum Schönberg sterben mußte...

Pierre Boulez' musikhistorische Selbstverortung um 1950

Verfasser der Beiträge 